\title{
REVISIONISM REVISED? AIRLINE DEREGULATION AND THE PUBLIC INTEREST*
}

\author{
Michael E. Levinet
}

From the Progressive Era through the 1950s, we thought we understood regulation. It was generated, we knew, by problems with laissez-faire. These problems came to be known as "market failures." Regulation operated to cure market failures by substituting the expert planning decisions of an administrative agency for the defective allocations of the failed market. ${ }^{1}$ Regulators sifted facts, rendered and explained their judgments, and generally did a creditable, if flawed job, or so we thought. This view of the origins and operation of the process came to be known as the "public interest" theory of regulation.

By the late 1950s, this view of the process began to change. An outpouring of scholarly work continuing through the 1960 s and into the 1970 s suggested that regulation did not work very well. As scholars examined the record of regulated industries, they found prices which were too high or too low, distorted allocations, mercantile protection, suppression of innovation, extension of regulation beyond the bounds of any known market failure, and protection of entrenched interests, corporate or geographic from any change at all costs. ${ }^{2}$

* Copyright 1981 by Duke University.

† Henry R. Luce Professor of Law and Social Change in the Technological Society, California Institute of Technology and Professor of Law, University of Southern California. An earlier and less complete version of this paper was delivered at the Conference on Managing the Transition to Deregulation, held at Duke University, May 7-8, 1980. Michael J. Graetz and Alan Schwartz, my colleagues at Caltech and U.S.C., were extremely generous with their help and provided many useful comments.

1. See, e.g., K. C. Davis, Administrative Law Treatise (1958); J. C. Bonbright, Principles of Public Utility Rates (1961). F. H. J. Friendly, The Federal. Administrative Agencies: The Need for Better Definition of Standards (1962). The theory was still alive, at least for polemic purposes, in 1970. See R. C. Fellmeth, The Interstate Commission 1 (1970). By 1972, Davis was far more reserved about the public interest character of regulation. See K. C. Davis, Administrative LAw Text (3rd ed. 1972) at 3-6.

2. The literature is enormous. A good sample of it can be found in the volumes of the Journal of Law and Economics and The Bell Journal of Economics, but it would be literally impossible to cite all of the literature. See, e.g., S. G. Breyer \& P. W. Macavoy, Energy Regllation by the Federal. Power Commission (1974); P. W. MacAvoy, The Economic Effects of Reciulation: The Trunkline Railroad Cartels and the ICC before 1900 (1965); P. W. MacAvoy \& J. Sloss, Regllation of Transport Innovation: The ICC and Unit Coal Trains to the East Coast (1967); J. Meyer, M. Peck, J. Stevenson, and C. Zwick, The Economics of Competition in the Transportation Industries (1959); R. G. Noll; M. J. Peck \& J. McGowan, Economic Aspects of Television Regulation (1973); S. Peltzman, Regulation of Pharmaceutical Innovation: The 1962 Amendients (1974); Joskow, Inflation and Environmental Concern: Structural Change in the Process of Public Utility Price Regulation, 17 J. L. \& Econ. 291 (1974); Kitch, Regulation of the Field Market for Natural Gas by the Federal Power Commision, 11 J. L. \& ECoN. 243 (1968); Levine, Is Regulation Necessary? California Air Transportation and National Regulatory Policy, 74 Yale L. J. 1416 (1965); Plott, Occupational Self-Regulation: A Case Study of the Oklahoma Dry Cleaner, 8 J. L. \& Ecos. 195 (1965); W. D. Montgomery, "Case Study of Regulatory Programs of the Federal Energy Administration," in the Committee Print Study on Federal Regulation, U. S. Senate Committee on Governmental Affairs, app. to Vol. 6. $729-833$ (Dec. 1978). 
In the face of these discoveries, the public interest theory did not survive. The scholarly view of the regulatory process changed from one of control of private behavior for the public benefit to one of use of governmental powers for private or sectional gain. ${ }^{3}$ This pattern emerged frequently enough to inspire speculation about the "true" sources of regulation and about the "true" motives of regulators. While no single explanation gained unanimous acceptance, a kind of "cluster consensus" appeared. This consensus characterized regulation as a device used by relatively small subgroups of the general population, either private corporations or geographic or occupational groups, to produce results favorable to them which would not be produced by the market. The regulatory services provided were variously described as organization of a cartel, wealth transfers as a form of "taxation," enshrinement of capitalistic class interests, or preservation of congressional and bureaucratic power. ${ }^{4}$ Of course, all gains, whether from regulation or the market, are in a sense realized by private human beings. The operational significance of this view of regulation is that government processes are used by organized subgroups of the population to enforce inefficient arrangements which transfer wealth or power to them..$^{5}$

By 1976, Roger Noll, in a survey of theories of regulation and administrative behavior, could describe public interest theories as "traditional" and "no longer widely shared." 6 Another commentator began a 1977 article on regulation as follows: "It seems fair to say that among economists the most widely accepted theory of government regulation is that, as a rule, regulation is acquired by the industry regulated and is designed and operated primarily for its benefit." cally, as this new academic consensus emerged, the Securities and Exchange Commission (SEC) deregulated brokerage commissions, a thirty-five-year-old system of agriculture price supports was largely dismantled, airlines were deregulated, the Federal Communications Commission (FCC) deregulated the communications equipment business and cable television and began to consider (along with Congress) deregulating common-carriage message service, and the Interstate Commerce Commission (ICC) and the Senate started to deregulate trucking. None of these events is predicted or explained very well by revisionist theories of regulation. At a minimum, some modification of revisionist theory is called for. Alternatively, one arguably might predict and explain this activity by reviving the public interest

3. For a useful analysis of the shift from public interest theories of regulation to revisionist theories, see Posner, Theories of Economic Regulation, 5 BELL J. EcoN. \& MGMT. Sci. 335 (1974).

4. Peltzman, Toward a More General Theory of Regulation, 19 J. L. \& Econ. 211 (1976); Posner, Taxation by Regulation, 2 Bell J. Econ. \& MGmt. Sci. 22 (1971); Stigler, The Theory of Economic Regulation, 2 Bell J. Econ. \& Mgmt. Sci. 3 (1971).

5. This article focuses specifically on price and entry regulation of the traditional variety. Many of the basic revisionist insights (and the modifications here) apply as well to safety and environmental regulation (e.g., Peltzman's analysis of the 1962 FDA amendments, supra note 2), but in focusing on the CAB, this article leaves for subsequent efforts detailed application of its thesis to externality, informational and safety regulation.

6. R. Noll, Government Administrative Behavior and Private Sector Response: A Multidisciplinary Survey, California Institute Social Science Working Paper 62, 12 (1976) (available from Division of Humanities and Social Sciences, California Institute of Technology, Pasadena, California).

7. Migué, Controls Versus Subsidies in the Economic Theory of Regulation, 20 J. L. \& EcoN. 213 (1977). 
theory of regulation in a modified form: namely, by asserting that both Congress and agencies attempt to regulate business activities to promote general welfare, but are sometimes misled by private or sectional misrepresentations designed to secure governmental action favoring more narrow populations. Although these attempts to influence the regulatory process may succeed at first for Downsian ${ }^{8}$ reasons, mistakes (whether $a b$ initio or generated over time by technical or circumstantial changes) tend to be publicized and corrected. If true, this view of regulation would require us once again to recast the way we look at regulation.

Since the purpose of this article is to rescue for reexamination a widely discarded public interest theory, I do not propose to pursue in detail here the modifications of revisionist theory. There are, however, modification strategies which might suggest themselves to one so inclined: One could, for example, attempt to reconcile recent deregulations with revisionist theory by asserting that scholarly work assessing the effects of regulation makes information on its impact available to the electorate at lower cost than previously, thus reducing the investment necessary to becoming an informed voter. Abetting this, one might argue that increasing over time the educational level of the electorate has further lowered the cost of informing voters. And finally, one might argue that modifying Downs' model to eliminate a principal weakness, namely its inconsistency in dealing with the fact that many people vote who "shouldn't", by positing an electorate educated to value voting intrinsically might reduce even further (by creating economies of scale in voting once they have decided to go to the polls) the cost to consumers of casting one of many votes against regulatory policies with adverse but diffuse effects on them.

An important feature of this last approach is that it assumes "public," rather than private, motivation (voting as a public obligation on issues of low salience under circumstances where no individual vote is likely to make a difference to the outcome) on the part of voters and hence weakens a linchpin of Downsian analysis. In particular, if the private maximizing assumption can be modified to accommodate otherwise "irrational" citizen voting, on what grounds can we exclude modifying assumptions about politician behavior to include political activities undertaken for generalized public, rather than concentrated private, gain? To open up this possibility is to propose to "save" revisionist theory by partially abandoning its most characteristic assumption. Such a modified Downsian approach then tends to converge with the sort of Downs-modified public interest theory discussed in this article. In this sense, the analysis put forward below not only further develops public interest theories but can also be useful in refining Downsian approaches

8. A. Downs, An Economic Theory of Democracy, at chs. 6, 13 (1957).

9. Downs himself acknowledges that a voting population following his model would have difficulty sustaining democracy because few rational voters would find it in their interest to vote (A. Downs, supra note 8 , at 267-70. He deals with the problem by postulating an interest in long-term survival of democracy which motivates some to vote. He calls this "long-run participation value," $i d$. at 270 . But, in the next sentence, he recognizes that free-rider effects vitiate even this motivation for voting. Downs is finally left with the bare assertion that at least some of the electorate will find it in their long or short-run self-interest to vote, id. at $270-271$. 
directly, even though direct exploration of modifications of Downsian theories is outside the scope of this article.

This paper will focus on airline deregulation in an initial attempt to explore the public interest hypothesis. To do so, we must develop at least a working definition of "public interest" regulation and give operational meaning both to this definition and to the revisionist theory in the specific context of airline deregulation. Then we can look at the facts of airline deregulation to see which characterization best fits and explains the events we have observed. ${ }^{10}$ If this inquiry establishes that a revised version of the public interest theory is more consistent with recent airline regulation evidence than are revisionist theories, examples from other agencies should be examined in future work to see whether a general theory can be supported.

There have been many contributors to the revisionist literature on regulation, but examination of the literature exposes common themes arrayed along a central line of development. The central notion underlying virtually all revisionist theory comes from Downs. ${ }^{11}$ Downs posits a government run by individuals trying to maximize a private, rather than public, utility function. In effect, he asks us to view public officials not as officials primarily concerned with public matters, but rather as private individuals trying to maximize their own utility much in the way a firm maximizes profits. Just as businessmen compete with other businessmen to accumulate consumer dollars which will bring them wealth, politicians compete with each other for electoral support which keeps them in office (their "wealth") and bureaucrats deal with the public and the legislature to accumulate power, prestige, tenure, et cetera. From this, it follows that public officials will try to assemble coalitions of support. Individuals and groups support public officials whose actions make those individuals or groups better off, either financially or by satisfying their "tastes" for public policies.

But supporting an official-even if only by voting-entails costs which will be borne willingly only if the payoff from a public policy to an individual or group exceeds the cost of supporting the public official who will implement it. Accordingly, those willing to put the most effort into supporting public officials are those whose gains from a particular policy most exceed the cost of implementing it, and public officials can gain support best by inventing or supporting policies which

10. Rejecting capture versions of the revisionist theory and accepting their public interest predecesstor are, of course, two distinct matters. One can view recent evidence as being inconsistent with those revisionist theories which characterize agencies as providing a service for the industries they regulate without being willing to rehabilitate public interest theories. See, e.g., Anderson, Who Owns the Regulators?, 4 Wharton Magazine 14-21 (1980) which uses recent history to reject the "capture" and "industry service" theories, but goes on to elaborate a substitute that owes more to Niskanen (agencies operating to maximize the amount of resources they control, Niskanen, BurEaucracy and Representative GovernMENT (1971)), Downs (regulators operating on their own behalf as private utility maximizers rewarded in power and jobs, rather than as public welfare maximizers, A. Downs, INside Bureaucracy, 81-86 (1967)), and Peltzman (agencies maximizing power and guaranteeing continued existence by intervening to transfer wealth on behalf of interests identified according to specified variables, Peltzman, supra note 4) than it does to any version of public interest theory.

11. A. Downs, supra note 8 . 
provide disproportionate benefits to groups who are in a position to affect political outcomes by delivering votes (or money to attract votes) or by supporting the activities of an agency.

Using this central notion, one can proceed to derive the central themes of the revisionist view of regulation. Policies which generate economic profits (rents) are likely to gain support from the groups in whose favor the profits will be distributed. One method of generating rents is to limit entry into an industry and to facilitate price coordination. According to Stigler, groups which can benefit from this kind of intervention use the political process to persuade legislators to create regulatory agencies to accomplish it. ${ }^{12}$ These groups are ordinarily private firms. If a group of users or a geographic area has low enough organization costs compared to potential benefits from intervention, it too will influence the political process to intervene in markets for the group's benefit. Generally, this intervention will take the form of what Posner has called "taxation by regulation," "1: namely, use of the regulatory process to generate monopoly profits from users who are not specially organized in order to finance excess service (compared to revenues) for the favored group or geographic area.

Kolko $^{14}$ has developed a revisionist account of the origins of regulation which is essentially Marxist in its use of class concepts, but which produces results strikingly similar to the Downsian line of development. He posits capitalists who find market competition unprofitable and consumer sovereignty unattractive and who seize control of the apparatus of the state in order to establish and preserve monopoly positions. In order to succeed politically in doing so, they exploit populist sentiment which favors controlling monopolies through regulation. Thus, regulatory mechanisms are created, supposedly to satisfy popular demand, but actually to permit capitalists to use the government to eliminate market forces which operate to reduce their profits.

Revisionist accounts of the legislative origin of regulation are integrated with revisionist accounts of agency-created regulation by Fiorina and Noll. ${ }^{15}$ They describe a process in which legislators who want to be reelected discover that individual service to constituents (and particularly help to constituents having difficulty with government agencies) is a particularly effective form of vote-getting, not least because it cuts across party lines and issue positions. At the same time, bureaucrats who wish to continue in their jobs and who favor their own continued intervention into the economy discover that it is in their interest to be responsive to inquiries from legislators on behalf of their constituents. And, of course, potential beneficiaries continue to be interested in interventions which will transfer wealth to them. The result, as seen by Fiorina and Noll, is a powerful conjunction of forces in favor of establishing and continuing regulation. Legislators, bureaucrats, and favored constituents unite to create complex programs which transfer wealth. The

12. Stigler, supra note 4 .

13. Posner, supra note 4.

14. G. Kolko, Railroads and Regulation (1965); G. Kolko, The Trilimph of Consfryatism (1963).

15. Fiorina \& Noll, Majority Rule Models and Legislative Elections, 41 J. Pot.. 1031.1099 (1976). 
legislator gets credit every time he helps a constituent deal with bureaucratic complexity independently of the position he or the constituent take on the desirability of the underlying program. The bureaucrat gets to run a bigger program, organized in ways that increase his discretion. Any constituent benefited by the program, of course, remains in favor of it. Any constituents who oppose a program in general but who can benefit from assistance in dealing with it ignore those general views in favor of supporting legislators whose help is financially more salient to them-incumbents who know their way around the bureaucracy. So powerful is this combination that Fiorina and Noll predict that rational legislators will choose voluntarily to make a program of intervention more complicated, discretionary, administrative, and "regulatory" than it need be to accomplish its purpose, because doing so maximizes the political advantage to be gained from it.

In summary, examining revisionist theories of regulation, reveals a great many common threads; revisionist theories owe a great deal to Downs. They posit groups with relatively low organization costs relative to their possible gains from political intervention who become disproportionately influential in the political process. These groups persuade Congress to set up a framework which will transfer wealth to them through the regulatory process. If the group is a private firm or firms, the government service may take the form of a cartel run at public expense. If the groups are user or geographic in nature, the regulation often will take the form of what Posner has called "taxation," generating monopoly profits from some disfavored sector of the public and transferring them as excess services for the benefit of the favored sector. A Marxist such as Kolko may describe all this in class terms rather than the more general Downsian analysis, but the end result is largely the same. And, finally, Fiorina and Noll describe an elaborate interaction of legislators, bureaucrats, and favored groups joining hands to achieve wealth transfers through the regulatory process which will redound to the credit of the legislators and to the vocational benefit of the bureaucrats.

These theories of regulatory genesis are closely related to theories of regulatory behavior. The cartel theory of origin generates a corresponding view of agency behavior which has a counterpart in the "capture" theory. ${ }^{16}$ The capture theory seems implicitly to accept the possibility of a public interest view of agency origin

16. M. Bernstein, Regulating Business by Independent Commission (1955). One anonymous regulator described the operation of the capture process as follows:

It all begins when a fellow out in Indianapolis is designated to be a member of a regulatory commission. First he gets into the going-away period. There are banquets in his honor, and the women say to his wife, "For goodness sake, be sure to tell us what Pat is really like." She demurely replies, "I am sure I won't see her often," believing, of course, that she will. After the goodbyes, the fellow comes to Washington and assumes his role as a member of a commission, believing that he is really a pretty important guy. After all, he almost got elected to Congress back home in Indiana. He is used to public attention. But after a few weeks in Washington, he realizes that nobody ever heard of him or cares much what he does-except one group of very personable, reasonable, knowledgeable, delightful human beings, who recognize his true worth. Obviously, they might turn his head just a bit.

R. Noll, Reforming Regulation 100 (1971). 
but postulates that, whatever the reasons that may have created a regulatory agency, it becomes captured by the industry it regulates and acts as a protector and cartel manager for that industry. A refinement of this view has the agency operating to continually shift resources in somebody's favor, thus maximizing its political power. The beneficiary of the wealth shift will change from producers to consumers to subgroups of consumers, depending on demand shifts and technical changes, but the wealth shifts will be undertaken without regard to efficiency. ${ }^{17}$

This view, in turn, is buttressed by Fiorina's ${ }^{18}$ general theory of the interaction between Congress and bureaucrats. Fiorina postulates that legislators win reelection by influencing governmental processes which affect wealth to operate in their constituents' favor. For such influence to be possible, government intervention in the form of regulation needs to exist and the regulators need to be cooperative in the way they carry out their mandate. Thus, the "iron triangle" 19 of legislators, regulators, and beneficiaries affects the operations as well as the geneses of regulatory agencies. Some theories of regulation postulate regulatory activity as an essentially defensive response to external pressures or signals. ${ }^{20}$ Others have suggested that regulation can be made so complex and formalized that it operates as an employment project administered by and for the benefit of lawyers. ${ }^{21}$ And Mashaw has given an account of regulatory genesis and operation which combines problem misperception, urgency, and misplaced confidence in government efficacy to produce regularized patterns of regulatory inefficiency. ${ }^{22}$

The problem with these theories is that they cannot accommodate, or can accommodate only with extreme difficulty, moves by regulators or Congress away from regulation and toward efficiency and reduction in bureaucratic discretionary power. The cartel theory and theories of bureaucratic power-maximizing and the "iron triangle" do not seem to allow for reductions in the amount of regulatory activity. Peltzman's more generalized wealth-transfer theory ${ }^{23}$ seems to allow for a certain amount of bureaucratic (as distinct from legislative) transfers in favor of the public, but not for relaxation of bureaucratic controls or dismantling of the apparatus. Theories of agency reaction to outside pressure would not seem to suggest deregulation in the face of strong unanimous industry opposition. The lawyer-employment theory would account for deregulation activity only if lawyers had a remarkably high discount rate and were prepared to accept gratefully the jobs created by a major brawl over deregulation at the expense of the stream of employment created by the continued existence of a regulatory agency and a Bar to deal with it. And Mashaw's complicated account ends with a whimper rather

17. Peltzman, supra note 4 .

18. M. Fiorina, Congress, Keystone of the Washington Establishment (1977).

19. Fortune, May 7,1979 , at 168, col. 2.

20. Noll, supra note 6 , at 23 .

21. Id. at 24-32.

22. Mashaw, Regulation, Logic and Ideology, Reculation, Nov.-Dec. 1979, at 44, col. 1.

23. Peltzman, supra note 4; see also, Anderson, supra note 10, for a bureaucratic powers maintenance theory of agency behavior which is also, it seems to me, damaged by the existence of reforms that weaken agencies drastically or cause them to disappear, let alone agency support of those reforms. 
than a bang, with the disillusioned public waiting exhausted and demoralized for a new (and presumably equally flawed) regulatory process cycle. None of the theories suggests that efficiency will be a prime focus or effect of congressional or regulatory concern with continued government intervention in the economy.

A major problem with theories of regulation is that they are difficult to express in forms which are rich enough to avoid caricature and yet sufficiently defined to be refutable. ${ }^{24}$ This seems to be especially true of the public interest theory. Formal efforts to define a social welfare optimum (the "public interest") proceed by specifying the effect of each alternative world-state on each individual. Then, depending on the analyst, one continues either by comparing these effects across individuals or by refusing to do so and accepting as superior only those worldstates that improve (or at least do not worsen) the lot of each individual in the society. A third possibility is to compare states of the world according to an objective standard (conformity with religious law, for example) and ignore its effects on individuals. Accordingly, to determine formally whether a proposed action is in the public interest seems to require a definition of the public interest which either is independent of private interests or is linked to private interests through a social welfare function. In a complicated world, few actions benefit everyone. And there is rarely sufficient agreement on intrinsic values to allow judgment of outcomes independently of their effects on individuals. And even where a Pareto-superior alternative to the status quo exists, it cannot be the automatic choice (using effects on individuals as a guide) if it benefits some individuals less than they would be benefited under other, more skewed, arrangements or if there is more than one Pareto-superior choice, each with its own constellation of bigger and smaller winners. So an action's "unweighted" effects on individuals cannot determine whether it is in the public interest. And attempting to weight those interests with a social welfare function (a systematic method of comparing and summing individual utilities to determine collective good) suffers from the defects which were the subject of Arrow's famous "impossibility" proof, ${ }^{25}$ from which formal escape has so far eluded an army of scholars. ${ }^{26}$

What then can we mean by regulation "in the public interest"? Suppose we sidestep formal specification and look at the problem paradigmatically. At least three paradigms could be appealed to in asserting that some exercise of the power of the state is in the public interest. There is an efficiency paradigm which, crudely stated, says that government activities which increase output are generally in the public interest. There is a distributional paradigm whose exact content, even expressed crudely, is the subject of great debate. Basically, it says that distributional effects are considered in determining the public interest only to the extent that they exceed a threshold which justifies intervention by the state and then to the extent that they involve making a specially favored group wealthier or a disfavored

24. Posner, supra note 3 , at 343,348 .

25. K. Arrow, Social. Choice and Individual Values 96-100 (2d ed. 1963).

26. Plott, Axiomatic Social Choice Theory: An Overview and Interpretation, 20 AM. J. PoL. Sci. 5 (1976). 
group poorer. There is probably agreement that infants and the congenitally infirm are among the favored classes and that criminals (that is, those committing specific acts which are regarded as punishably immoral) are to be disfavored. After that, there is much dispute, but fairly wide recognition that there are at least some favored groups and some disfavored groups, and that it is the proper business of government to shift wealth toward the former and away from the latter. Indeed, even Nozick, who is widely thought to represent the minimalist end of the spectrum in terms of his willingness to redistribute, agrees (however reluctantly) that there is at least one possible group in favor of whom intervention is justified. ${ }^{27}$

This brings us to a third paradigm, the process paradigm, which says that government intervention designed to improve efficiency or (especially) to redistribute wealth must be undertaken in accordance with governmental processes accepted as fair, and that even actions which otherwise resemble the efficiency and distributional paradigms will not be in the public interest if they are not undertaken in a way which satisfies the process paradigm. The reason that actions taken under the distributional paradigms are singled out for emphasis in accordance with the process paradigm may lie in a recognition that the sum of efficiency improvements over time is likely to benefit everyone at least a little, while it is very unlikely that the same will be true of the sum of distributional adjustments. Consensus on the application of the distribution or efficiency paradigms is often hard to achieve, so that achieving process acceptability is necessary to ensure acceptance of government actions justified by reference to the first two paradigms.

Using a paradigmatic approach hardly allows us to escape all our problems. The entire range of judgments necessary to determine formally or informally whether an action is in the public interest is beset with difficulties. Some are so fundamental as to be essentially unmanageable. For example, when we talk about "efficiency," we must make a whole set of assumptions which we know are incorrect as matters of fact. We know that price is not equal to marginal cost everywhere in the economy, but attempts to take seriously the general theory of second best and derive policy implications from it have not been very successful. When we talk about distributional fairness, we know that individual utility functions are not independent, that A's level of satisfaction with any given bundle of wealth is often closely linked to how well $\mathrm{B}$ is doing. But we do not have any systematic way of taking this into account which avoids paradox. When we talk about process fairness, we know that the procedures used to reach a result may profoundly influence the outcome, yet we cannot construct a neutral agenda.

All we can do in cases like these is to acknowledge the problem with regret and then fall back on the need to continue to say something about an important human activity. In this connection, many will find comforting the fact that many of the predictions derived from flawed positive theories are borne out reasonably well in practice, and that many of the normative judgements produced by applying flawed

27. R. Nozick, ANarchy, State, and Utopla 152.53 (1979), 
value structures through flawed procedures seem to command fairly widespread allegiance. As Stigler, in a remarkably candid moment, once allowed:

What can the economist respond to a person (say a psychiatrist) who insists that he does not maximize utility? It would be easy to persuade him that he does not minimize utility: after all he is alive, and not drinking crankcase oil. It would also be possible . . . to point to empirical implications of the assumption, but since these implications began to be developed only about 40 years after the theory was proposed (1871), what led economists to accept it?

The main reason was introspection. Everyone has irrational foibles: a common one is to refuse to put extra postage on a letter if one does not have the exact denomination, thus saving one or two cents, at the cost of a more expensive special trip to the post office. Yet, by and large, our actions are geared to the goals we seek to achieve. Introspective evidence will never convince a skeptic, and perhaps the only remarkable thing about introspection on utility maximizing is that virtually every economist found it convincing over so long a period. ${ }^{28}$

There are other problems which seem less fundamental. In the end, techniques used to deal with them differ from those we use to deal with the ur-problems only in that we are less anxious when we use them. For example, one could object that the public interest paradigm may well have the features posited above, but that establishing the content of the public interest paradigm does not also establish that people engaged in considering or evaluating regulation actually use this paradigm in doing so. Once again, one probably can never convince a committed skeptic. But repeated and persistent use of public interest language by both proponents and opponents of regulation leaves one with the choice of either assuming that they are proceeding with reference to the "public interest" language they are using, or adopting the more heroic position that, when they talk about public interest, they are pursuing something else. In fact, Posner has identified the tendency toward the latter as a weakness in revisionist theory. ${ }^{29}$

All this allows us to assert operationally that regulation which reduces efficiency while redistributing wealth in favor of a group not widely accepted as especially deserving is not in the public interest. It follows also that governmental activity which increases efficiency while redistributing in favor of a group widely regarded as deserving is in the public interest. No activity undertaken outside acceptable process limits (e.g., through secret influence or bribery) ordinarily is regarded as in the public interest. After that, and particularly when the activity results in consequences which can be characterized as "efficient but maldistributed," or "inefficient but fair," the matter becomes much harder. But, even in such hard cases, argument proceeds by reference to the paradigms. Thus, an advocate of a program argues that his group is deserving and downplays inefficiencies, or an advocate for a broader consumer group will tend to emphasize the efficiencies that will be produced by a proposal and tend to minimize distributional impacts on specific groups. And if fraud is to be undertaken in the pursuit of public policy, it centers on false claims of efficiency or of misrepresentation of beneficiaries (as when

28. G. Stigler, The Theory of Price 59-60 (3d ed. 1966).

29. Posner, supra note 3 , at 355 . 
agribusinesses use the plight of nearly nonexistent poor family farmers to justify a crop or water subsidy). As noted above, this paradigmatic approach has the virtue of being consistent with the public-interest-dominated rhetoric of debates about regulation, where the revisionist theories must postulate not merely some fraud and dissembling in debate, but an entire process which fraudulently avoids discussing the "real" issues at stake. ${ }^{30}$

So, public interest theory of airline regulation would posit that, unless it either increased efficiency or provided a wealth shift in favor of a group recognized by consensus as worthy of support, or (preferably) both, airline regulation could not be created or, if created (by mistake or by pressure designed to mislead Congress), could not be maintained.

With this in mind, let us examine airline deregulation and, through it, the genesis of airline regulation itself. Both Civil Aeronautics Board (CAB)-initiated and congressionally-mandated revisions in domestic airline regulation had the following characteristics unaccounted for by revisionist theories:

(1) They involved less control, not more, over the activities of the airline industry. This gave the agency and Congress less discretion and less ability to deliver services to geographical constituents or private firms who had previously benefited from the exercise of regulatory discretion. It diminished considerably the power of the agency to create economic rents or to transfer wealth. ${ }^{31}$

(2) Airline deregulation reduced both the size and the power of the CAB. ${ }^{32}$

(3) Airline deregulation was promoted as efficiency-increasing and was administered to pursue that goal. Deviations that were made from promoting efficient outcomes were made knowingly and as minor exceptions to insure the political survival of a program that, on the whole, removed many more redistributionist interventions than it added. For example, the small communities service guarantee program written into the Act removes the Board's power to create rents and transfer them through cross-subsidy. It requires the $\mathrm{CAB}$ to identify explicitly the service it is subsidizing and the cost to the taxpayer for providing such service. By revisionist analysis, this should reduce the Board's ability to overprovide service, since the overprovision can be identified readily and its cost known to those who support it without benefiting from it. ${ }^{33}$ And, in fact, since deregulation, subsidized service has been tailored

30. Id. Posner identifies the rhetoric problem, and attempts a revisionist reconciliation.

31. Airline Deregulation Act of 1978, P.L. 95-504, 92 Stat. 1705; especially 92 Stat 1744, 1745, 1746, 1747, 49 U.S.C. 1551. This act ends government economic regulation of both entry and rates by 1983 and mandates the demise of the Civil Aeronautics Board (CAB) by 1985 . In the interim, it also reduces considerably $\mathrm{CAB}$ discretion in dealing with many other previous objects of regulation such as charter flights, agreements between airlines, mergers, et cetera.

32. Id.

33. See the new $\$ 419$ of the Federal Aviation Act of 1958 as amended by the Airline Deregulation Act of 1978 (49 U.S.C. 1389) and compare it to the broad discretion embodied in "old" $\$ 406$ (49 U.S.C. $1376(1958))$. 
much more closely to actual demand than was previously the case.

(4) The political appeal of airline deregulation was to a large, undifferentiated mass of airline consumers, many of whom were not regular users. If anything, heavy business users of airline services may have lost through deregulation subsidies in the form of excessive service frequency and seat access which were being supported to them by overcharging infrequent discretionary travelers. ${ }^{34}$

(5) The airline industry resisted deregulation strenuously. This industry was well organized and well financed and, by Downsian analysis, should have been disproportionately influential in the legislative and regulatory process. But its preference for contrived regulation violated both the efficiency and distribution paradigms of the public interest theory articulated above. ${ }^{35}$

(6) After initial resistance, the CAB not only supported, but actively promoted, airline deregulation and its own sunset in $1985 .^{36}$ This is not accounted for by revisionist histories of regulation, nor is either CAB support for deregulation nor the ultimate congressional endorsement of deregulation easily reconciled with "iron triangle" theories.

How can we accommodate these awkward events within the existing consensus theories about regulation? Perhaps one could explain that those in charge of the $\mathrm{CAB}$ during the relevant period were not "typical" bureaucrats because they were tenured academics or "professional deregulators"37 or both. But this explanation has several difficulties. First, the revisionist theories of regulation do not posit the character of the bureaucrats as a variable. ${ }^{38}$ Rather, they posit basic forces, acting on agencies and on the Congress, which will produce the results they predict regardless of who is running the agency or, alternatively, which will operate to select regulators who are comfortable "delivering the goods" in accordance with revisionist theories. In a sense, the character of bureaucrats is for the revisionists a dependent, rather than independent, variable. Second, deregulation was supported by former practicing (nontenured) lawyers John Robson in the Ford administration and Marvin Cohen, Alfred Kahn's successor, as well as by other members of the Board and the Board's staff. Their backgrounds were fairly typical of those appointed to or staffing regulatory commissions, and they certainly did not all have assured fall-back alternatives. Could they all have been atypical? And if it is possible for an entire agency to be atypical in a fundamental way for a period of four years, how robust can the consensus theory of agency behavior theory be?

34. G. Douglas \& J. Miller, Economic Regllation of Domestic: Air Transportation 87-94, 103 (1974)

35. A. Downs, supra note 8.

36. Aviation Regulatory Reform: Hearings on H.R. 11145 Before the Subcomm. on Aviation of the House Comm. on Public Works and Transport., 95th Cong., 2d Sess. 122-186 (1978) (testimony of Alfred Kahn, Chairman CAB).

37. Anderson, supra note 10 , at 19.

38. Supra note 4. 
Imposition of airline deregulation over the opposition of the industry and the aviation bar is flatly inconsistent with the Stigler hypothesis and the capture hypothesis. It is possible to explain in terms of the lawyer-dominance hypothesis, the Peltzman hypothesis, and the Posner taxation hypothesis only if the actors and claimants preferred to play in one spectacular, but short-lived, "Götterdämmerung," rather than an essentially endless series of more modest dramas. Eliminating rate regulation ${ }^{39}$ on the upside as well as the downside is difficult to reconcile with the Peltzman modification of the Stigler theory, since it leaves the agency in no position to continue to alternate in bestowing benefits on the industry and user groups. Entry control was eliminated without any clear knowledge on anyone's part as to which firms would benefit and which would be harmed. What had been established by the California and Texas examples was that less control on entry would benefit the public and some firms which were difficult to identify, probably at the expense of other established carriers. ${ }^{40}$

But all of these awkward facts are consistent with a story that goes something like this: In 1938, it appeared to the general public and the Congress that uncontrolled markets did not work very well for the public over the long run. Although markets produced low prices during the Depression years, many producers went out of business. The airline business was relatively new, Congress had little experience with it, and there was no reason not to apply general skepticism about markets to airlines. Doubts about airline markets were reinforced by the fact that firms were continuing to attempt entry. Notwithstanding this dismal picture, a modern analyst would say that these firms were looking past the Depression at a bright future for a new technology. But it seemed to Congress that mistakenly optimistic entrepreneurs were seeking profitable operations where none were possible, draining away resources needed for further extension of the airline system in fruitless and profitless competitive struggles for existing business. Firms which had invested substantial resources in pioneering air transportation would become the innocent victims of still another example of market competition run riot.

It was therefore not difficult for the airline industry to persuade Congress and the public that the fledgling airline industry would go the way of many other Depression-era firms and that the full potential of aviation could not be developed in a free-market environment. This would be both inefficient and unfair. Whether the industry sincerely believed this, merely hoped for the benefits of cartelization, or both, is immaterial. It made its case. Trucking had been regulated too recently for the deleterious long-term effects of regulation to become known. The enormous overinvestment in railroad plants ${ }^{41}$ masked any rents that ICC railroad regulation might have been generating for private firms. The damage to the

39. Posner, supra note 29.

40. Levine, supra note 2. See 1 Oversight of Civil Aeronautics Board Practices and Procedures: Hearings Before the Subcomm. on Administrative Practice and Procedure of the Senate Comm. on the Judiciary, 94th Cong., 1st Sess. 525-33 (1975) (statement of Charles A. Murphy).

41. Hilton, The Consistency of the Interstate Commerce Act, 9 J. L. \& EcoN. 87, 110 (1966). 
interests of the public as a whole from cross-subsidy, as well as its limited effectiveness in securing the desired services, were not well understood, while regional infrastructural development through public intervention had been characteristic of anti-Depression strategy. And there was enough faith in what Mashaw has called "the ideology of government efficacy" 42 for the Congress and the public to believe that an expert agency could secure for the public most of the benefits of competition without subjecting the public to the disadvantages of its "excesses."

Whatever its vices, this story has the singular virtue of being consistent with the legislative history of the 1938 Act. $^{43}$ This history, which many (including myself ${ }^{44}$ ) have tried with only indifferent success to square with the Stigler governmentservices theory, contains numerous statements (including Senate floor manager McCarran's well-known remarks denying that entry control would protect incumbents from the threat of future competition ${ }^{45}$ ) which seem to suggest that Congress was not intentionally freezing entry nor thereby creating a cartel for the sole benefit of the airlines and a few isolated geographic areas. While it is not hard for an experienced observer of the legislative process to generate the cynicism necessary to turn the legislative history as it is into one that will support the currentlyheld theory of regulatory origin, less adjustment of this history is required to accept the modified public-interest hypothesis. This modified theory says that airline regulation was imposed by a Congress which, while attempting to act in the public interest, made a mistake.

Of course, the industry was eloquent in its predictions of the benefits of regulation and of the ruin impending without it. But most of those arguments were cast in a form designed to appeal to the efficiency paradigm or, alternatively,

42. Mashaw, supra note 20 , at $\mathbf{5 8}$.

43. See C. S. Rhyne, Civil Aeronautics Act Annotated (1939); see also 83 Cong. Rec., parts 5-10 (1938).

44. E.g., Levine, supra note 2, at 1420; Levine, Regulating Airmail Transportation, 18 J. L. \& EcoN. 317 , $325(1975)$.

45. 83 Cong. Rec. 6852 (1938).

It is the public in whom we are interested: that is the primary consideration. The bill has in contemplation that service (to the public) all the way through, but. together with that, we must remember that those who sought to serve the public in this field, either under no law at all or under the existing law, which is known as the McKellar-Black law, or other existing laws, should have some recognition as pioneers, we will say. There is nothing in this bill and nothing in the spirit of the bill or in the philosophy of the bill that would take from those pioneers anything that they have established. On the other hand, we desire to give them the best of "the break," if I may use a common expression.

Again referring to public necessity and convenience, permit me to use an illustration with which the Senator is familiar. If it could be established to the satisfaction of the Authority which is about to be set up that another line could well be operated from Chicago to Salt Lake City, although that same territory is now served by the United Air Lines, and the demand for service was so great as to support another line, then the Authority could investigate, reach a determination, establish a rule, and could say, "There is sufficient demand, there is sufficient patronage, and there is sufficient commercial life to sustain the other lines. Therefore we can grant a franchise to another line." But before that could be done, full and complete hearings would have to be had. So we are trying to set up a non-political agency that will go into matters such as the one I have tried to illustrate, and if the circumstances do not justify another line, say "No, you cannot go in; you cannot set up another line, because if you do both lines will fail; both lines will go out of business, and the public that we are looking to primarily will not be served." That is the object and purpose of this entire bill. It is not to say that any line may be "frozen" or that any line may be perpetuated, nor that any monopoly over any terrain may be established to the exclusion of the necessity which the public may present. 
to line up the industry as a worthy secondary legatee in its own right with the traveling and shipping public, the post office, and the national defense as the prime beneficiaries of a governmentally-stabilized airline industry. The revisionist account requires that we posit that, in seeking regulation, the administration and the members of Congress were motivated primarily by the potential wealth gains to the industry, and that all were cynical enough to focus their rhetoric principally on public gains known to be illusory. An experienced Washington observer probably would not want to reject such a possibility out of hand for an individual instance; but, as a general hypothesis, it is sufficiently strained that one would wish to assert it only if the evidence seemed to require it. Before the recent spate of deregulations justified on public-interest grounds, the evidence seemed that way to many of us. But the material presented here on airline deregulation suggests that perhaps public interest rhetoric accurately reflects the intentions of legislators and bureaucrats much more often than we had supposed. Using hindsight, the "obvious" benefits to the public may have been greatly overstated, but it is surely simpler and more consistent with a long view of the evidence to assume mistake on the part of a Congress and a Roosevelt administration trying to benefit the public at large than to insist on the existence of a widely-coordinated effort by government to transfer wealth from the general public to the airlines.

Over time, scholarly assessments of the performance of the regulated industry suggested that airlines operated better without regulation. Congressional leaders thought it politically beneficial, and perhaps even consistent with their legislative duty, to make changes which might benefit the public. Although the factors described by Downs, ${ }^{46}$ Posner, ${ }^{47}$ and Stigler ${ }^{48}$ undoubtedly affected both the original legislation and its revision, those forces (in the form of industry and sectional pressure for favored treatment) operated as a deflection rather than the main thrust of either regulation or its revision. In the meantime, this scholary output, as well as observations that all was not as well as it could be in the regulated industry, led to the appointment of regulators who were prepared to make important changes in the direction of efficiency, even at the expense of agency power.

In the executive and administrative contexts, Robson and the Ford administration began the process of educating Congress and the public to the ills produced by airline regulation and to the potential benefits of deregulation. Senator Kennedy gave the process major impetus in the Senate through the 1975 hearings before his Subcommittee on Administrative Practice and Procedure. ${ }^{49}$ Certainly the industry opposed deregulation, as did many members of Congress and the public, and this opposition was reflected in the timidity of the CAB's early efforts, as well as in the restrained tone of early legislative proposals. But at least some of the industry and public opposition, and much of the congressional skepticism, stemmed from

46. Supra note 4 .

47. Id.

48. Id.

49. Oversight of Civil Aeronautic Board Practices and Procedures: Hearings Before the Subcomm. on Administrative Practice and Procedure of the Senate Comm. on the Judiciary, 94th Cong., 1st Sess. (1975). 
uncertainty about the effects of dismantling a system that had produced at least minimally satisfactory results for forty years. This uncertainty was reinforced by the fact that the particular misallocation produced by $\mathrm{CAB}$ regulation had been airline service which was better in many respects than that which the market otherwise would have provided at high prices that excluded many potential customers. Since the service was present, identifiable and tangible, while the price savings and the excluded masses were hypothetical and not associated with easily identifiable individuals, would-be deregulators had a difficult time convincing skeptics of the "if it ain't broke, don't fix it" genre. In fact, the demonstrable price and service benefits of California and Texas intrastate experiments with competition were probably indispensible to the task of persuading skeptics that the apparently satisfactory $\mathrm{CAB}$-regulated system, in fact, was not functioning in the public interest.

But the telling fact for our purposes is that this initially doubtful congressional faction (including Senator Cannon, the powerful chairman of both the Aviation Subcommittee and the full Commerce Committee) ultimately helped control the legislative process in favor of deregulation, which by then was perceived to be in the public interest. And it did so in the face of diehard opposition by factions (including the industry) whose positions were undermined by the ultimate transparency of the degree to which their positions were motivated by purely private, rather than "public-interest" considerations of gain and loss. And, on the administrative side, even conceding that Chairman Kahn and his chief staff aides had relatively little to lose by the diminution of $\mathrm{CAB}$ power, these changes were supported by an initially skeptical but ultimately convinced career staff and by members of the Board who were prepared to see their own power diminished for the benefit of the public.

This scenario may seem painfully quaint to most readers. It is certainly not self-evidently correct. But it is consistent with the rhetoric of the legislative and administrative history, with the facts of airline deregulation, and with the existence of a broader movement to deregulate other industries as well. Ockham's razor ${ }^{50}$ (the principle that simple explanations are to be preferred to complicated ones, all else being equal), if nothing else, requires that we give serious attention to this hypothesis. And this account of the dynamics of airline regulation is consistent with preliminary work done by Mashaw, ${ }^{51}$ with respect to the origins of the $1962 \mathrm{drug}$ regulation, and by Kitch, ${ }^{52}$ with respect to the origins of the ICC Act.

Much work needs to be done. As always, it will be done better if performed with an open mind. Ultimately, it may be possible to synthesize a modification of the public-interest theory using the work that forms the underpinning of the current consensus on regulation. Such a synthesis will not require us to revise

50. E. A. Moody, William of Ockham, in 8 The Encyclopeda of Philosophy 306, 307 (reprint ed. P. Edwards, 1972).

51. Mashaw, supra note 22

52. E. Kitch, Economics of the Interstate Commerce Act of 1887 and Its Antecedents (1979) (unpublished manuscript in M. E. Levine's files, copy available on request). 
carefully buttressed scholarly views of the inefficiency of regulation or co deny that there exist powerful incentives for private groups to attempt to obtain particular regulatory benefits. But a new public interest theory will require us to reassess the prospects for the persistence of regulation demonstrated to be inefficient and undesirable. In this as well as other areas, it may be that the political process produces better results than theorists can account for. 
